\title{
Association of Superior Vena Cava Syndrome with Sleep Apnea: Investigation Using an Impulse Oscillometry System
}

\author{
Masanori Yokoba $^{1,2^{*}}$, Naohito Ishii ${ }^{1}$, Tsuyoshi Ichikawa ${ }^{3}$, Mayuko Wada ${ }^{2}$, Hisashi Mitsufuji ${ }^{2}$, \\ Masaru Kubota ${ }^{2}$, Noriyuki Masuda ${ }^{2}$, Masato Katagiri ${ }^{1,2}$ \\ ${ }^{1}$ School of Allied Health Sciences, Kitasato University, Kanagawa, Japan; ${ }^{2}$ Division of Respiratory Medicine, Kitasato University \\ Hospital, Kanagawa, Japan; ${ }^{3}$ Graduate School of Medical Sciences, Kitasato University, Kanagawa, Japan. \\ Email: "myoko@kitasato-u.ac.jp
}

Received March $16^{\text {th }}, 2012$; revised April 28 ${ }^{\text {th }}, 2012$; accepted May $15^{\text {th }}, 2012$

\begin{abstract}
Superior vena cava syndrome (SVCS) patients sometimes show signs of obstructive sleep apnea (OSA). However, the mechanism causing hypoxia during sleep in SVCS patients is still uncertain. The aim of this study was to elucidate 1) the changes in central and peripheral respiratory resistance with SVCS; and 2) interpret the mechanism underlying the development of hypoxia during sleep in patients with SVCS related to OSA. Ten SVCS patients related to a neoplasm were recruited for this study. The degree of apnea hypopnea index (AHI) for OSA was evaluated by portable diagnosing device before and after SVCS treatment. We also analyzed the airway resistance and reactance quantitatively in the supine position by Master Screen impulse oscillometry system (MS-IOS ${ }^{\circledR}$ ). After SVCS treatment, mean values of AHI were significantly decreased from 30.9 to 16.9 (/hour) $(\mathrm{p}=0.001)$. Central respiratory resistance $(\mathrm{R} 20)$ also decreased significantly from 0.40 to $0.33 \mathrm{kPa} / \mathrm{L} / \mathrm{s}(\mathrm{p}=0.025)$ in the supine position. In contrast, peripheral respiratory resistance (R5-R20) and distal capacitive reactance (X5) did not change significantly. It is thought that the exacerbation of OSA due to SVCS is caused by increasing upper airway resistance related to reversible edema of the upper airway mucous or tissue. In contrast, SVCS may not cause peripheral respiratory tract and lung parenchyma edema.
\end{abstract}

Keywords: Upper Airway Resistance; Central Respiratory Resistance; Peripheral Respiratory Resistance; Impulse Oscillometry System; IOS; Pulmonary Neoplasm

\section{Introduction}

Superior vena cava syndrome (SVCS) can occur from extrinsic compression by a primary lung or mediastinal neoplasm, mediastinal lymph node metastasis, a benign tumor or intraluminal thrombosis [1-3]. It is known to cause facial and upper extremity edema and to affect patients' quality of life and prognosis [4]. Most obstructive sleep apnea (OSA), which causes sleep disturbances, is caused by anatomical and functional issues with the upper airway [5]. Few clinical cases have been reported about OSA caused by SVCS [6-8]. OSA and sleep deprivation increases the risk of hypertension, cardiovascular disease, diabetes mellitus and depression [9-12] which causes a lack of motivation for cancer treatment [13], and also decrease blood leukocyte and lymphocytes [14] which may impede cancer therapy. However, the changes in OSA and respiratory resistance caused by SVCS before and after SVCS treatment have not been extensively

${ }^{*}$ Corresponding author. evaluated. Currently, impulse oscillometry system (IOS) was introduced for evaluate the respiratory resistance. This new oscillation technique can separate the respiratory resistance into central and peripheral part, thereby allowing the source of the resistance to be determined. This also allows us to measure the airway resistance not only in sitting position, but also in supine posture. The purpose of this study was to elucidate the changes in central and peripheral respiratory resistance and apnea hypopnea index (AHI) with and without SVCS, and interpret the mechanism underlying the development of hypoxia during sleep in patients with SVCS related to OSA.

\section{Patients and Methods}

Ten patients, who were diagnosed as having superior vena cava syndrome (SVCS) related to a malignant neoplasm and admitted to our university hospital between 2005 August and 2010 April, were recruited for this study. Subjects underwent portable screening tests to 
establish whether or not they had OSA. Patients with bronchial stenosis caused by direct invasion or lymph node metastasis from the neoplasm, lymphangitis carcinomatosa, chronic heart failure, cerebral vascular disease, or chronic renal failure, were excluded from this study. Written informed consent was obtained from all patients, and this study was approved by the Kitasato University Hospital Research Ethics Committee.

\subsection{Evaluation of the OSA}

The subjects underwent an overnight sleep study with a portable sleep monitoring device for diagnosing sleep apnea syndrome. The device included a thermistor and/or nasal pressure monitor for oronasal airflow and a pulse oximeter to examine oxygen saturation as well as the two elastic bands to monitor their chest and abdominal movement (Apnomonitor $5^{\circledR}$, Chest Co., Tokyo, Japan). The data were analyzed not only using a computer, but also manually by a laboratory technician to ensure that the severity of the OSA was not over- or underestimated. The apnea hypopnea index (AHI) was calculated before and after SVCS treatment.

\subsection{Evaluation of the Respiratory Resistance and Reactance}

R20 (central respiratory resistance), R5-R20 (peripheral respiratory resistance) and X5 (distal capacitive reactance) were evaluated using a Master Screen impulse oscillometry system (MS-IOS, Viasys ${ }^{\mathrm{TM}}$ Healthcare, Inc., Höchberg, Germany) before and after SVCS treatment in supine positions.

\subsection{Impulse Oscillometry System (IOS)}

IOS is a reliable method to determine respiratory mechanics during quiet resting breathing. This technique does not require a patient's cooperation, as swallowing esophageal balloon. It allows us to obtain the data not only in sitting position, but also in supine position like during sleep [15]. The impulse-shaped, time-discrete external forcing signal generated by the loud speaker contained a frequency distribution in the range of 5 to 35 Hz. The transducer that was connected to the Lilly-type heated screen pneumotachograph measured mouth pressure and total flow. The signals generated by the loud speaker are considered for impedance calculation (respiratory impedance: $\mathrm{Zrs}=$ pressure/flow). The impedance parameter is further analyzed for the "real" in-phase component (resistance: Rrs) and the "imaginaly" out-ofphase component (reactance: Xrs) of pressure and flow. Rrs is one of the indexes of airway resistance that includes central and peripheral airways, lung tissue and chest wall resistance. Xrs means distal capacitive reactance represents hyperinflation or restriction. In IOS, low frequency oscillations (i.e. $5 \mathrm{~Hz}$ ) are transmitted to the lung periphery, while those at frequencies $\geq 20 \mathrm{~Hz}$ are thought to be damped out before reaching the peripheral airway [16]. Therefore, it is thought that R20 means central respiratory resistance and R5-R20 means peripheral respiratory resistance. The reactance at $5 \mathrm{~Hz}$ (X5) may be determined by homogeneous distribution of ventilation, effective ventilation capacity, and compliance of the lung and chest wall. These indices have been shown to be useful for the evaluation of upper airway patency in OSA $[17,18]$.

\subsection{Statistics}

The data were analyzed using the SPSS for Windows software package (Version 11.0; SPSS, Inc., Chicago, IL, USA). Mean values for AHI, and mean values for R20, R5-R20 and X5 in the supine positions were compared for before and after SVCS treatment by Wilcoxon's signed rank test.

\section{Results}

The patients' characteristics are summarized in Table 1. A total of 10 subjects ( 8 males, 2 females; age: $48-69$ years; height: 148.0 - $175.5 \mathrm{~cm}$; weight: $42.0-72.4 \mathrm{~kg}$ ) were enrolled in this study. Eight of the 10 patients had primary lung cancer ( 1 adenocarcinoma, 3 squamous cell carcinoma and 4 small cell carcinoma) and two had been diagnosed with thymic cancer. Symptoms and signs what they showed are dyspnea and orthopnea (7 subjects), hoarseness ( 2 subjects), headache (1 subject), facial edema ( 9 subjects), upper extremity edema (8 subjects), jugular venous distention (5 subjects) and venous distention on the chest wall (5 subjects). SVCS was treated with a SVC metallic stent alone (3 subjects), chemotherapy alone (4 subjects), irradiation alone (1 subject), or a SVC metallic stent plus chemotherapy (2 subjects). Sleep studies revealed that all of the patients had OSA before SVCS treatment (AHI $30.9 \pm 15.1 / \mathrm{hr}$, mean \pm SD). After SVCS treatment, all of symptoms and signs were disappeared, and body weight and body mass index were decreased significantly from $60.9 \pm 8.8$ to $57.2 \pm 7.2 \mathrm{~kg}$ (p $=0.001)$ and $22.2 \pm 2.7$ to $20.8 \pm 2.0 \mathrm{~kg} / \mathrm{m}^{2}(\mathrm{p}=0.002)$ with resolving facial and upper extremity edema. None of patients felt excessive daytime sleepiness and accepted to use continuous positive airway pressure (CPAP) therapy. Even without using CPAP therapy, the mean values of AHI significantly improved to $16.9 \pm 13.4 / \mathrm{hr}$ ( $\mathrm{p}=$ 0.001) (Figure 1(a)) when SVCS had been treated. The R20 was also improved significantly from $0.40 \pm 0.11$ to $0.33 \pm 0.09 \mathrm{kPa} / \mathrm{L} / \mathrm{sec}(\mathrm{p}=0.025)$ (Figure $1(\mathbf{b}))$ after 
Table 1. Patient characteristics before SVCS treatment.

\begin{tabular}{|c|c|c|c|c|c|c|c|c|c|c|}
\hline No. & Age & Gender & $\begin{array}{l}\text { Height } \\
(\mathrm{cm})\end{array}$ & $\begin{array}{l}\text { Body Weight } \\
(\mathrm{kg})\end{array}$ & $\begin{array}{c}\mathrm{BMI} \\
\left(\mathrm{kg} / \mathrm{m}^{2}\right)\end{array}$ & $\begin{array}{l}\text { AHI } \\
(/ h r)\end{array}$ & Type of SA & Diagnosis & $\begin{array}{c}\text { Smoking } \\
\text { (pack-years) }\end{array}$ & Treatment for SVCS \\
\hline 1 & 48 & $\mathrm{~F}$ & 157.4 & 59.5 & 24.0 & 15.5 & OSA & Thymic cancer & 0 & Metallic stent + chemotherapy \\
\hline 2 & 66 & $\mathrm{~F}$ & 148.0 & 42.0 & 19.2 & 20.1 & OSA & Thymic cancer & 7.5 & Metallic stent \\
\hline 3 & 50 & M & 175.5 & 65.0 & 21.1 & 37.3 & OSA & SCLC & 75 & Chemotherapy \\
\hline 4 & 59 & M & 171.0 & 50.0 & 17.1 & 21.0 & OSA & NSCLC (Ad.) & 20 & Metallic stent \\
\hline 5 & 50 & M & 164.0 & 63.0 & 23.4 & 12.6 & OSA & NSCLC (Sq.) & 67.5 & Irradiation \\
\hline 6 & 52 & M & 175.0 & 69.0 & 22.5 & 56.3 & OSA & SCLC & 35 & Chemotherapy \\
\hline 7 & 51 & M & 170.8 & 63.6 & 21.8 & 26.4 & OSA & SCLC & 30 & Chemotherapy \\
\hline 8 & 67 & M & 163.3 & 72.4 & 27.1 & 28.1 & OSA & NSCLC (Sq.) & 138 & Metallic stent + chemotherapy \\
\hline 9 & 69 & M & 165.4 & 61.0 & 22.3 & 53.5 & OSA & NSCLC (Sq.) & 40 & Metallic stent \\
\hline 10 & 55 & M & 165.0 & 63.6 & 23.4 & 38.0 & OSA & SCLC & 35 & Chemotherapy \\
\hline Mean & 56.7 & - & 165.4 & 60.9 & 22.2 & 30.9 & ------- & --------- & --------- & ----- \\
\hline SD & 8.0 & - & 8.1 & 8.9 & 2.7 & 15.1 & ------ & --------- & --------- & ---------- \\
\hline
\end{tabular}

NSCLC: non-small cell lung cancer; SCLC: small cell lung cancer; Ad.: adenocarcinoma; Sq.: squamous cell carcinoma; BMI: body mass index; SA: sleep apnea; OSA: obstructive sleep apnea; AHI: apnea hypopnea index.

SVCS treatment. In contrast, R5-R20 and X5 did not change significantly with SVCS treatment (Figures 1(c) and (d)).

\section{Discussion}

In this study, it was revealed that the all SVCS patients had obvious OSA during sleep before SVCS treatment. Their SVC stenosis were treated with a SVC metallic stent alone (3 subjects), chemotherapy alone (4 subjects), irradiation alone (1 subject), or a SVC metallic stent plus chemotherapy (2 subjects). None of patients use CPAP machine, but all of patients showed 1) Decreasing AHI; 2) Improving central respiratory resistance (R20); and 3) No remarkable alteration on peripheral respiratory resistance (R5-R20) nor distal capacitive reactance (X5) with SVCS treatment. The impulse oscillometry system (IOS) measurement is non-invasive, and none of the patients in our study complained about the examination.

It goes without saying that polysomnography (PSG) is essential for the diagnosis of sleep apnea hypopnea syndrome. However, we were concerned that PSG may disturb the usual sleep of the subjects, because it uses more complicated monitoring cables than the portable sleep monitoring device used for the SVCS patients. Currently, several investigators have reported no significant differences in the values of the apnea index, hypopnea index, AHI, mean $\mathrm{SpO} 2$ or Lowest $\mathrm{SpO} 2$ between the data obtained by PSG and those obtained by the portable sleep monitoring device $[19,20]$. Hence, it is thought that the diagnostic ability of those two methods is thus comparable [20,21]. As a result, we decided to use the Apnomonitor $5^{\circledR}$ instead of PSG in this study.

To our knowledge, only 7 prior cases of OSA in SVCS patients have been reported in the literature [6-8,22-25]. For one of these patients with lung cancer, it was reported that the severity of OSA was decreased with SVCS improvement [24]. In our study, we observed that the facial and upper limb edemas were improved and AHI were decreased significantly in all of the patients when SVCS was treated, even without CPAP therapy. It has been thought that anatomic narrowing, and differences in compliance, reflex, and respiratory muscle variables are important for the development of OSA because they affect the caliber and function of the upper airway [26]. It was confirmed histologically that there was interstitial edema with mild inflammatory reaction present in the surgical specimens obtained from the upper airway of OSA patients by using non-laser-assisted uvulopalatopharyngoplasty. This investigation also identified that there was no fat present in any of the specimens [27]. Hutt et al. [28] reported that the palatal airway became more edematous than any other upper airway segment when anesthetized sympathectomized cats underwent nitroprusside related pharyngeal blood volume increases. Parisi et al. [29] also reported a 7 percent increase in pharyngeal volume of normal awake humans after local application of the vasoconstrictor phenylephedrine. It was also reported that fluid displacement from the legs by lower body positive pressure increases neck circum- 


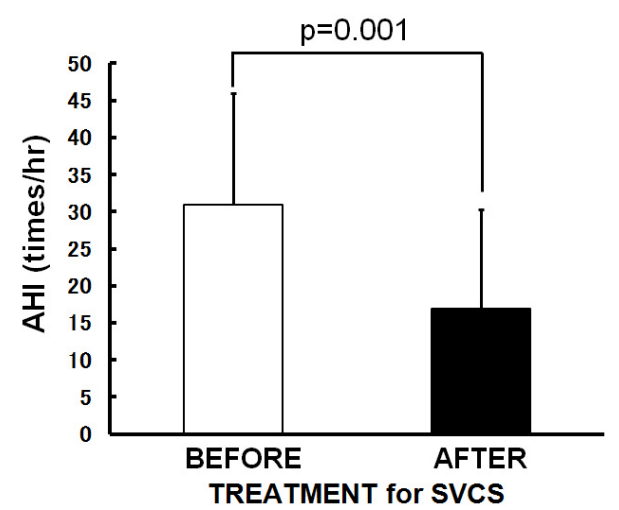

(a)

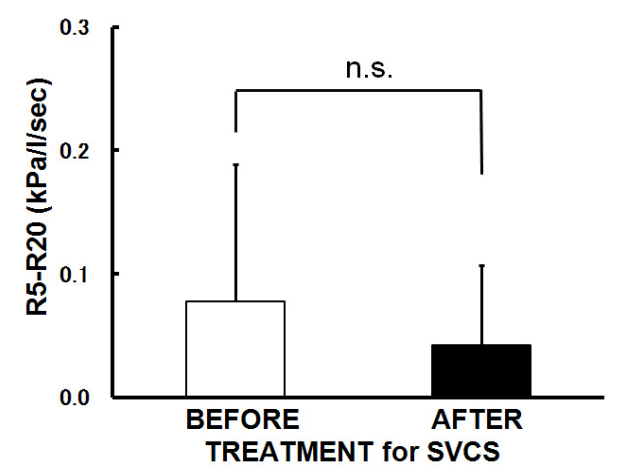

(c)

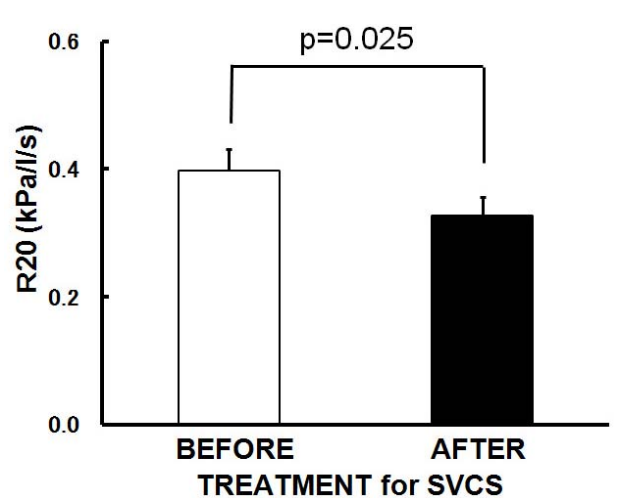

(b)

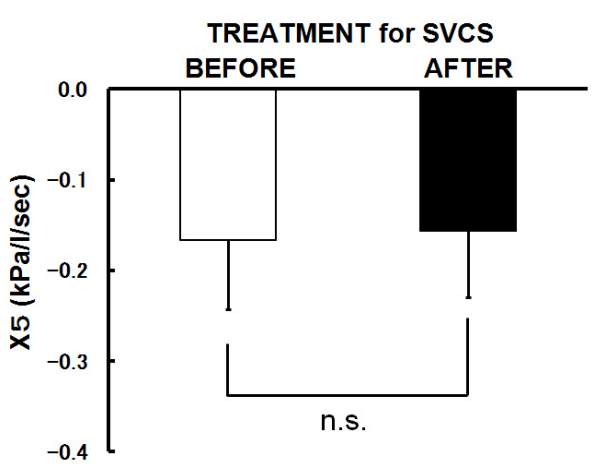

(d)

Figure 1. Changes in the mean values following SVCS treatment. After SVCS treatment, (a) AHI improved from $30.9 \pm$ $15.1 / \mathrm{hr}$ to $16.9 \pm 13.4 / \mathrm{hr}(\mathrm{p}=0.001)$; (b) $\mathrm{R} 20$ was significantly improved from $0.40 \pm 0.11$ to $0.33 \pm 0.09 \mathrm{kPa} / \mathrm{L} / \mathrm{sec}$ in $\mathrm{supine}$ position ( $=0.025)$; (c) R5-R20 did not change significantly; (d) X5 did not change significantly. Bars are the means + or SD.

ference, airway resistance of the pharynx, and upper airway collapsibility in healthy men [30,31]. However, influence of the SVCS or fluid displacement for the peripheral respiratory resistance and lung parenchyma had not been established. In our study, it was revealed that central respiratory resistances (R20) was decreased immediately upon improvement of SVCS. In contrast, SVCS did not affect either peripheral respiratory resistance (R5-R20) or distal capacitive reactance (X5). It seems that thickening of the soft tissue surrounding the airway caused by mucous or tissue edema contributes significantly to reversible upper airway resistance caused by pharyngeal airway narrowing in SVCS-related OSA patients. However, SVCS may not occasion mucous or tissue edema on peripheral respiratory tract and lung parenchyma.

In our study, it was revealed that SVCS exacerbate OSA. It may suggested that it is better to treat OSA until SVCS can be resolved or their sleep apnea will be improved (i.e. using CPAP therapy), because preventing sleep deprivation and promoting refreshing sleep might makes favorable immune status and remain patients' mental status better for struggling with cancer.

\section{Acknowledgements}

This study was supported by grants from Parents' Association Grant of Kitasato University, School of Medicine.

\section{Financial Disclosure and Conflicts of Interest}

None of the authors has a conflict of interest to be declared.

\section{Author Contribution}

Dr. Masanori Yokoba is the first author, contributed to concept and design of the study, and had full access to all the data in the study and takes responsibility for the integrity of the data and accuracy to the data analysis. Dr. Masato Katagiri, Dr. Noriyuki Masuda and Dr. Naohito Ishii contributed to concept and design of the study, interpretation of data, and critical revision of the manuscript. Mr. Tsuyoshi Ichikawa supported analyzing data statistically and interpretation of data. Dr. Mayuko Wada, 
Dr. Hisashi Mitsufuji, Dr. Masaru Kubota are attending doctors for the enrolled patients of this study, contributed to concept and design of the study, interpretation of data, and critical revision of the manuscript.

\section{REFERENCES}

[1] N. R. Barshes, S. Annambhotla, H. F. El Sayed, T. T. Huynh, P. Kougias, A. Dardik and P. H. Lin, "Percutaneous Stenting of Supyerior Vena Cava Syndrome: Treatment Outcome in Patients with Benign and Malignant Etiology," Vascular, Vol. 15, No. 5, 2007, pp. 314321.

[2] C. Lanciego, C. Pangua, J. I. Chacon, J. Velasco, R. C. Boy, A. Viana, S. Cerezo and L. G. Garcia, "Endovascular Stenting as the First Step in the Overall Management of Malignant Superior Vena Cava Syndrome," American Journal of Roentgenology, Vol. 193, No. 2, 2009, pp. 549-558.

[3] T. Takeda, M. Saitoh and S. Takeda, "Superior Vena Cava Syndrome Caused by an Intravascular Thrombosis Due to Underlying Prostate Carcinoma," Internal Medicine, Vol. 47, No. 22, 2008, pp. 2007-2009.

[4] S. Arinc, U. Gonlugur, O. Dervan, N. Erdal, F. Ece, M. Ertugrul, D. Derince, O. Oruc and A. Hazar, "Prognostic Factors in Patients with Small Cell Lung Carcinoma," Medical Oncology, Vol. 27, 2010, pp. 237-241. doi:10.1007/s12032-009-9198-8

[5] N. McArdle and N. J. Douglas, "Effect of Continuous Positive Airway Pressure on Sleep Architecture in the Sleep Apnea-Hypopnea Syndrome-A Randomized Controlled Trial," American Journal of Respiratory and Critical Care Medicine, Vol. 164, No. 8, 2001, pp. 1459-1463.

[6] B. Fernandez, L. A. Smolley, S. M. Swirsky and M. D. Kaye, "Relief of Sleep Apnea after Intravascular Stenting for Superior Vena Cava Syndrome," Vascular Medicine, Vol. 22, No. 4, 1999, pp. 33-36.

[7] J. R. Stradling, S. Huddart and A. G. Arnold, "Sleep Apnoea Syndrome Caused by Neurofibromatosis and Superior Vena Caval Obstruction," Thorax, Vol. 36, No. 8, 1981, pp. 634-635.

[8] Y. Ustundag, Y. Bayraktar and S. Emri, "Superior Vena Cava Thrombosis and Obstructive Sleep Apnea in a Patient with Familial Mediterranean Fever," American Journal of the Medical Sciences, Vol. 316, No. 1, 1998, pp. 53-55.

[9] J. P. Baguet, M. Nadra, G. Barone-Rochette, O. Ormezzano, H. Pierre and J. L. Pepin, "Early Cardiovascular Abnormalities in Newly Diagnosed Obstructive Sleep Apnea," Jouanal of Vascular Health and Risk Management, Vol. 5, 2009, pp. 1063-1073. doi:10.2147/VHRM.S8300

[10] N. Botros, J. Concato, V. Mohsenin, B. Selim, K. Doctor and H. K. Yaggi, "Obstructive Sleep Apnea as a Risk Factor for Type 2 Diabetes," American Journal of Medicine, Vol. 122, No. 12, 2009, pp. 1122-1127.

[11] T. A. Dernaika, G. T. Kinasewitz and M. M. Tawk, "Ef- fects of Nocturnal Continuous Positive Airway Pressure Therapy in Patients with Resistant Hypertension and Obstructive Sleep Apnea," Journal of Clinical Sleep Medicine, Vol. 5, No. 2, 2009, pp. 103-107.

[12] A. G. Wheaton, G. S. Perry, D. P. Chapman and J. B. Croft, "Sleep Disordered Breathing and Depression among US Adults: National Health and Nutrition Examination Survey, 2005-2008," Sleep, Vol. 35, No. 4, 2012, pp. 461-467.

[13] M. Colleoni, M. Mandala, G. Peruzzotti, C. Robertson, A. Bredart and A. Goldhirsch, "Depression and Degree of Acceptance of Adjuvant Cytotoxic Drugs," Lancet, Vol. 356, No. 9238, 2000, pp. 1326-1327.

[14] A. Zager, M. L. Andersen, F. S. Ruiz, I. B. Antunes and S. Tufik, "Effects of Acute and Chronic Sleep Loss on Immune Modulation of Rats," American Journal of Physiology-Regulatory, Integrative and Comparative Physiology, Vol. 293, No. 1, 2007, pp. R504-R509.

[15] H. J. Smith, P. Reinhold and M. D. Goldman, "Forced Oscillation Technique and Impulse Oscillometry," European Respiratory Monograph, Vol. 31, 2005, pp. 72-105. doi:10.1183/1025448x.00031005

[16] M. D. Goldman, C. Saadeh and D. Ross, "Clinical Applications of Forced Oscillation to Assess Peripheral Airway Function," Respiratory Physiology \& Neurobiology, Vol. 148, No. 1-2, 2005, pp. 179-194.

[17] C. C. Lin, K. M. Wu, C. S. Chou and S. F. Liaw, "Oral Airway Resistance during Wakefulness in Eucapnic and Hypercapnic Sleep Apnea Syndrome," Respiratory Physiology \& Neurobiology, Vol. 139, No. 2, 2004, pp. 215 224.

[18] J. Cao, C. Que, G. Wang and B. He, "Effect of Posture on Airway Resistance in Obstructive Sleep Apnea-Hypopnea Syndrome by Means of Impulse Oscillation," Respiration, Vol. 77, No. 1, 2009, pp. 38-43.

[19] E. Oostveen, D. MacLeod, H. Lorino, R. Farre, Z. Hantos, K. Desager and F. Marchal, "The Forced Oscillation Technique in Clinical Practice: Methodology, Recommendations and Future Developments," European Respiratory Journal, Vol. 22, No. 6, 2003, pp. 1026-1041.

[20] D. G. Spyratos, G. P. Glattki, L. T. Sichletidis and D. Patakas, "Assessment of Respiratory Mechanics by Impulse Oscillometry in Orthopneic Patients with Acute Left Ventricular Failure," Heart Lung, Vol. 40, No. 2, 2011, pp. 97-104.

[21] H. Yagi, S. Nakata, H. Tsuge, F. Yasuma, A. Noda, M. Morinaga, M. Tagaya and T. Nakashima, "Significance of a Screening Device (Apnomonitor 5) for Sleep Apnea Syndrome," Auris Nasus Larynx, Vol. 36, No. 2, 2009, pp. 176-180.

[22] M. Amemiya, A. Takise, K. Kaira, K. Endou, T. Horie and M. Inazawa, "Obstructive Sleep Apnea Syndrome in a Patient with Superior Vena Cava Syndrome Caused by Malignant Lymphoma," The Journal of the Japanese Respiatory Society, Vol. 44, No. 3, 2006, pp. 197-201.

[23] G. Fuyuno, R. Kobayashi, R. Iga, H. Nomori, K. Kodera and S. Morinaga, "Obstructive Sleep Apnea Syndrome 
Associated with Superior Vena Cava Syndrome," Nihon Kyobu Shikkan Gakkai Zasshi, Vol. 33, 1995, pp. 322326.

[24] M. Ito, J. Tanaka, K. Kubota, H. Sato, M. Takahashi, H. Tanaka, T. Ohdaira, H. Yoshizawa, Y. Muramatsu, M. Satoh, E. Suzuki, M. Arakawa and F. Gejyo, "Obstructive Sleep Apnea Syndrome in a Patient with Superior Vena Cava Syndrome Caused by Lung Cancer," The Journal of the Japanese Respiatory Society, Vol. 38, No. 6, 2000, pp. 471-475.

[25] A. Ursavas, M. Karadag, B. Burgazlioglu, F. Coskun, E. Ceylan, S. Onart and R. O. Gozu, "Relief from Sleep Apnea after Radiation and Chemotherapy," Clinical Lung Cancer, Vol. 8, No. 8, 2007, pp. 502-503.

[26] D. W. Hudgel, "Mechanisms of Obstructive Sleep-Apnea," Chest, Vol. 101, No. 2, 1992, pp. 541-549.

[27] G. E. Anastassov and N. Trieger, "Edema in the Upper Airway in Patients with Obstructive Sleep Apnea Syndrome," Oral Surgery Oral Medicine Oral Pathology Oral Radiology and Endodontics, Vol. 86, No. 6, 1998, pp. 644-647.
[28] D. A. Hutt, M. J. Wasicko, R. A. Parisi, J. A. Neubauer and N. H. Edelman, "Effects of Vascular Tone on Pharyngeal Size Independent of Skeletal Muscle Activity," American Review of Respiratory Disease, Vol. 139 (suppl), 1989, p. A374.

[29] R. A. Parisi, M. J. Wasicko, D. A. Hutt, M. Mandel, T. V. Santiago and N. H. Edelman, "Mucosal Vasoconstriction Increases Pharyngeal Size in Normal Subjects," American Review of Respiratory Disease, Vol. 139 (suppl), 1989, p. A374.

[30] K. L. Chiu, C. M. Ryan, S. Shiota, P. Ruttanaumpawan, M. Arzt, J. S. Haight, C. T. Chan, J. S. Floras and T. D. Bradley, "Fluid Shift by Lower Body Positive Pressure Increases Pharyngeal Resistance in Healthy Subjects," American Journal of Respiratory and Critical Care Medicine, Vol. 174, No. 12, 2006, pp. 1378-1383.

[31] M. C. Su, K. L. Chiu, P. Ruttanaumpawan, S. Shiota, D. Yumino, S. Redolfi, J. S. Haight and T. D. Bradley, "Lower Body Positive Pressure Increases Upper Airway Collapsibility in Healthy Subjects," Respiratory Physiology \& Neurobiology, Vol. 161, No. 3, 2008, pp. 306-312. 